\title{
Determining the Areas Suitable for Wind Farms Installation by Integrating Geographical Information System and Analytical Network Process (ANP)
}

\author{
Mohammad. Kamangar ${ }^{1}$ Shelir. Katorani ${ }^{2}$, Chia. Sohrabnezhad ${ }^{3}$ \\ ${ }^{1}$ phd. student in climatology of zanjan university, zanjan, iran. \\ ${ }^{2}$ Academic Center for Education, Culture and research (ACECR), kurdestan, iran \\ ${ }^{3}$ Academic Center for Education, Culture and research (ACECR), kurdestan, iran.
}

\begin{abstract}
Environmental pollution, price fluctuations and the futility of fossil fuels used in power plants have led to a shift to alternative energy sources. In recent years, wind power has been used as one of the most important sustainable energy sources for generating electricity. Choosing the right place to install wind farms is essential due to effect the location of the power plants imposes on the amount and cost of production and transmission of energy. Kermanshah province is located in western Iran, where growth of population and industry on the one hand and rising living standards on the other hand have led to an increase in electric energy demand. In this research, suitable sites for the installation of wind farms were determined in addition to identifying the important parameters in determining the appropriate locations due to the nonlinear relationships among the applied criteria. Moreover, the Analytical Network Process method was used to determine the importance of each criterion and Analytic hierarchy process was run to determine the classes of the criteria. By combining layers, the final map was prepared in four classes. The results indicated that about $404 \mathrm{sq}$. $\mathrm{Km}$ of the area is quite suitable. Also, the results of this method were investigated using ground control, which suggest that all selected criteria are met in suitable areas as well as the satisfactory use of Analytical Network Process method for locating wind farms.
\end{abstract}

Keywords: Renewable energy, wind, Analytical Network Process, Kermanshah.

\section{Introduction}

Energy is the source of all natural and human processes (Beheshti Far, 2010). The growing consumption of electrical energy and the low current generation of electricity will make the construction of new power plants inevitable. Today, we face two major challenges in meeting the demand for electricity from fossil fuels: the futility of fossil fuel and, more importantly, the effects of environmental pollution due to the use of fossil fuels (Resch, 2007). In order to realize the concept of sustainable development, it is essential to provide a base for estimating the required energy through the natural potential of each region. One of the best ways to supply energy is the wind energy that is produced by installing wind turbines. The rapid development of wind energy extraction technologies has made it a safer alternative to today's energy systems (Zhao et al., 2011). A bulk of countries have turned it over because of the easy installation and quick start up of wind turbines and the costs associated with the reduction of this type of energy Wolsnik, 2010). The use of wind energy increased by $50 \%$ between 2005 and 2010 (EWEA, 2010). The speed of installation and development of areas around these turbines has been very prominent (Lee et al, 2009). The development of the use of wind energy depends on environmental factors such as wind, access to the grid and population distribution, and the perception of how these factors affect the development of wind farms for planners who seek to install wind turbines in a specific area (McWilliams, 2012). Some people advocate the benefits of using wind energy, such as lack of greenhouse gases and low water consumption, and some oppose to it due to their visual impact on prospects and noise generation (Groothuis et al., 2008). Advantages and disadvantages of using wind energy as part of the issues should be taken into account in decision making (Tegou and Haralambopoulos, 2010). In this regard, Soltani et al. (2010) investigated the potential of wind energy in Amir Abad Port to install wind power plants. They calculated the coefficients of $\mathrm{k}$ and c Weibull for 58 months, from March 2005 to December 2009, and obtained the wind power density. According to the calculations, the average wind power density coefficient at 50 meters height was $97.97 \mathrm{~W} / \mathrm{m}^{2}$, which was one of the weak potential areas in the wind class. Given the calculations, the highest density was observed in July with 142.10 watts per square meter and the lowest in October i.e. about 62 watts per square meter. Noorallahi et al. (2011) carried out the potential of wind energy in the western region of Bactria using the GIS. In their methodology, technical, environmental, and economical importance criteria have been investigated and according to international standards with the aim of potentiometric identification of highimportance areas, these studies have shown that by assuming the use of the Turbine Gamesa G58 A maximum of $1897 \mathrm{MW}$ of wind power could be generated in the study area, which would provide $26 \%$ of the region's 
electricity at 1404 Horizons. In their research, Saeedi et al. (2011) showed that wind power density at 30 and 40 meters altitude for Bojnourd was 200 and $250 \mathrm{~W} / \mathrm{m}^{2}$, respectively. Also, wind power density for Esfarayen at two heights of 30 and 40 meters was 200 and 300 watts per square meter, respectively. This study showed that the installation of wind farms in these two cities of North Khorasan province is possible. Mohammadi et al. (2012) conducted a study based on wind direction and velocity data of Kermanshah, Eslamabad-e Gharb, Ravansar, Kangavar, and Sarpol-e Zahab stations during 1997-2006. The results of this research indicated that the three stations of Ravansar, Sarpol-e Zahab and Kangavar have a good potential for wind power generation. Eslamabad-e Gharb is suitable for wind power utilization when using high wind turbines, and Kermanshah has no potential to use wind energy. Nguyen (2007) examined wind power in Vietnam, resource assessment, development status and future requirements. He used the GIS to assess the resources. The findings of the study indicated that Vietnam has a good potential for wind power. Around 131,000 square kilometers of the region's land is available for developing wind energy, which produces 3,572 megawatts of electricity at 865 square kilometers, which is less than 6 cents per square kilometer. The study also shows that wind energy in Vietnam could provide electricity to 300,000 non-electric rural families. In the study entitled the development of the wind farms installation in Thailand using the GIS decision support system, Prabamroong et al. (2009) assessed the current situation and its outcomes. A total of 20 criteria for wind farms were selected in the system, each of which was limited to a level. Of the present analysis, after applying the criteria of the selected constraints, the percentage of the total probable area for installing a wind power plant with respect to the total area in each region is as follows: $95 \%$ of the central region, $88 \%$ of the East, $94 \%$ North, $79 \%$ Northeast and $91 \%$ South. The main criteria are the suitable places in rural areas (central, eastern, northeastern, and southern areas), forest (eastern, northeastern, and southern areas), national park and forest (central, northeastern, and southern) and Street networks (central and eastern). In his study entitled the development of wind energy in the world, Poland and Europe between 1995 and 2002, Michalak (2011) examined its current state and its future perspective and estimated that according to the EU's strategy, wind power generation by 2020 will account for about $20 \%$ of energy demand, and that countries with similar situations can use wind energy to accelerate their economic growth. In Iran, due to the abundance of traditional energy sources, less attention has been paid to renewable energy sources, and that dearth of research in this area is quite evident. The first step is to precisely study the potentials to develop the use of renewable energy sources (Dutra \& Szklo, 2008). Due to its huge wind power resources, Iran will have the ability to widely supply wind energy in the near future. This study sought to identify the primary factors affecting the location of wind power plants and the importance of the impact of different factors on location selection in optimal installation locations in socio-cultural, environmental and economic decision making approaches using Analytical Network Process and locating areas able to install wind farms in Kermanshah province.

\section{Materials and methods}

\subsection{The study area}

Kermanshah Province is located in the western region of Iran with 33 degrees 37 minutes to 35 degrees and 17 minutes north, 45 degrees and 20 minutes to 48 degrees and 1 minute east with about 24,500 square kilometers area (1.48 percent of the total area of the country) (Figure 1). The province is bounded to the north by Kurdistan province, from the south to the provinces of Ilam and Lorestan, from the east to Hamadan province, and from the west to Iraq. The average altitude of the province is $1200 \mathrm{~m}$ from the sea level and the average rainfall in the province is $400-500 \mathrm{~mm}$. Due to its wide latitude, it has a semi-arid, Mediterranean, semi-humid, humid sea. According to the latest census in 2011, the population of the province was estimated at about 2 million five hundred thousand people. In terms of administrative divisions of Iran, Kermanshah Province has twelve cities where Kermanshah is the capital of the province.

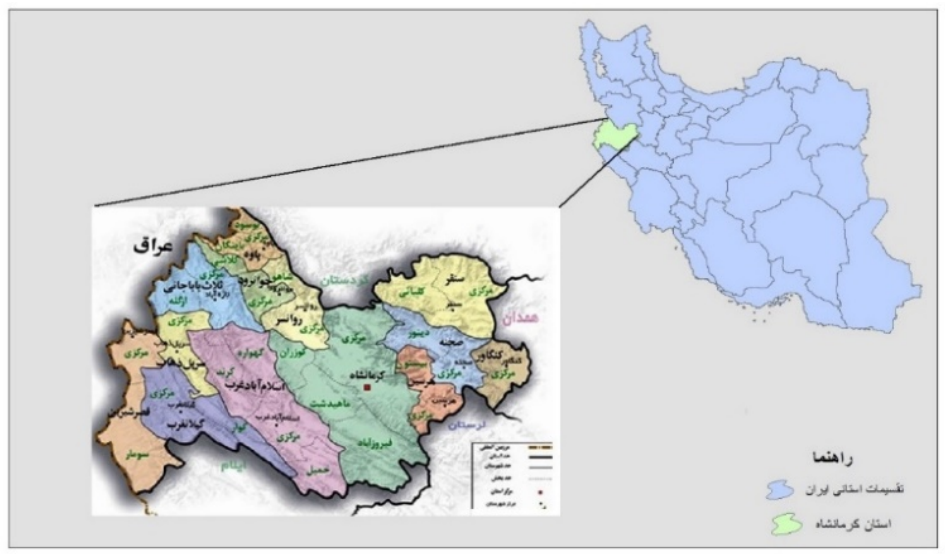

Figure 1: The location of Kermanshah province in the administrative divisions of Iran 
Due to the roughness of the province of Kermanshah and the presence of high altitudes in the vicinity of the plains, the wind blows during day and night. Most local winds occur in the winter and spring seasons. One of the most important winds of the province is the West wind, the north wind, and samūm wind.

\subsection{Information layers}

The first step in identification of areas is to determine the criteria involved in locating the power plants and then to rank those criteria (Jiang and Eastman, 2000). In this study, according to past studies by researchers, the opinion of the experts of Kermanshah Electrical Power Administration and the cognition from the province's environment based on geographic studies, the criteria for data preparation and modeling were selected. In the present study, the criteria were divided into three clusters of a: economic and technical clusters with sub criteria (1-wind density 2-slope 3-way 4-rainfall 5-distance from the city 6-land use) b: environmental criteria (7vegetation 8- distance from protected areas), and c: ground-related criteria (9-elevation 10-distance from fault 11-geology 12 geomorphology). The reasons behind the use of the desired layers and how they are created are briefly mentioned:

\subsubsection{Wind density}

The wind speed data from the Meteorological Organization of Iran were used to provide the wind velocity which represents the wind speed of the studied area. The wind speed data of 17 synoptic stations were studied in a 20-year statistical period. First, for each station, wind speed data was extracted for each month, and after averaging for each month, the average annual rate of all stations was calculated. Given that the annual and monthly variance of wind speed is significant in energy and electricity production, the monthly variance of stations was calculated. After calculating the average wind speed of each station, geometric fields or latitude and longitude were added to each station, then interpolation was done running Kriging method.

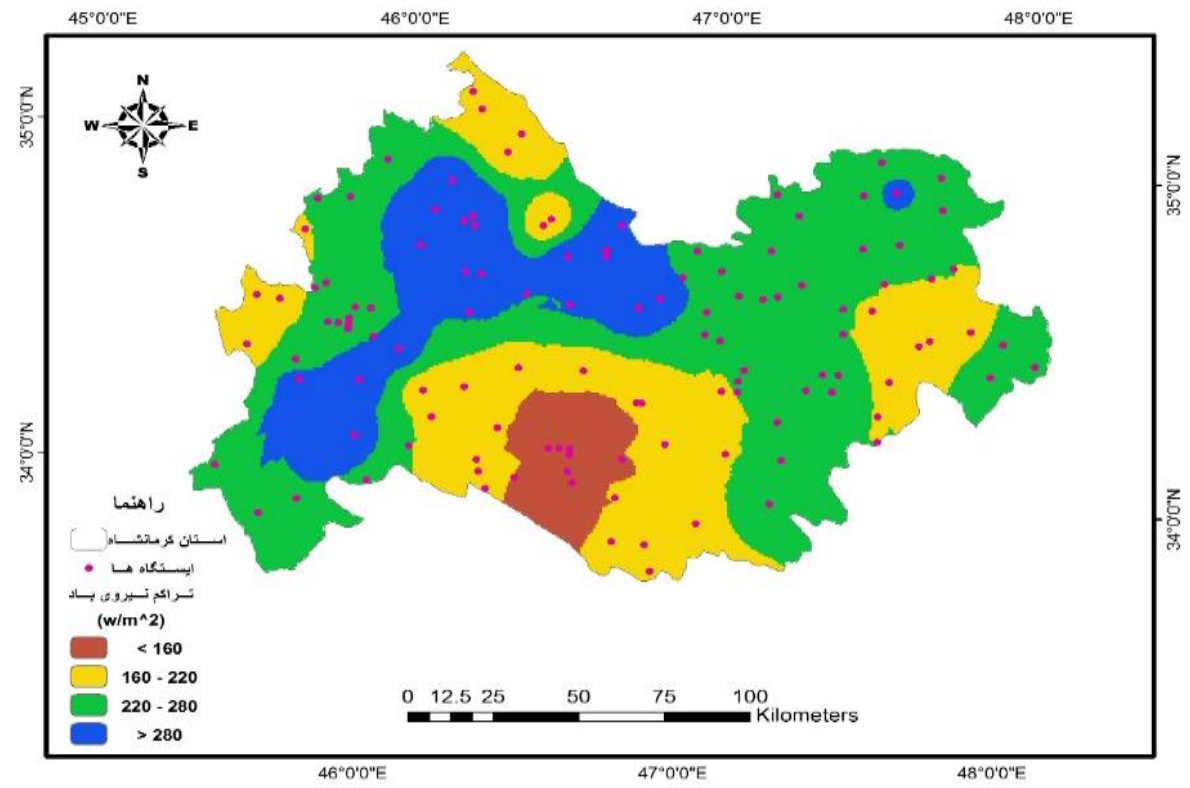

Figure 2: Classification of wind density in Kermanshah province

\subsubsection{Slope}

Slope can be calculated in terms of degree or percentage. Since the cost of wind turbines is different in different slopes, the extracted map is classified into four groups and given that wind turbines are not common in high slopes, so the values of high slopes are much lower than low ones. In fact, large slopes may hide turbines behind the hills or mountains and reduce the energy output of wind power. 


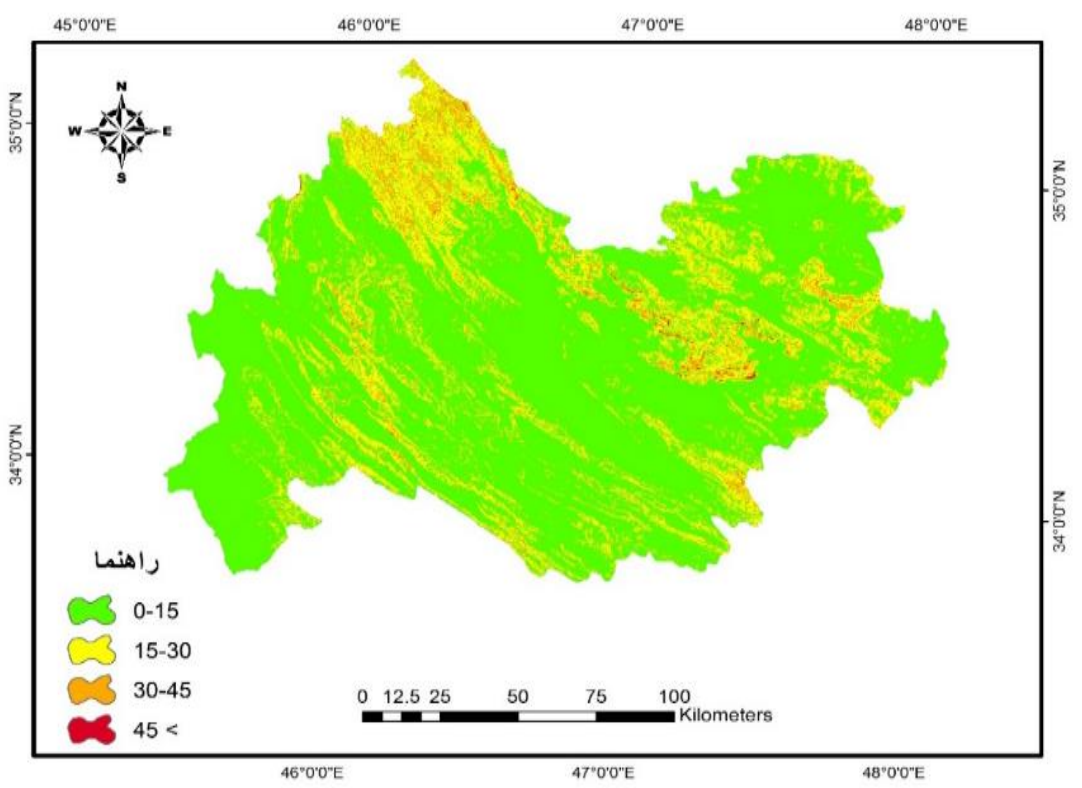

Figure 3: Slope layer classification in Kermanshah province

\subsubsection{Transportation layer}

Transportation network involves a network of road transportation, including highways, intercity roads, roadways, and railways. The transport network map for the construction of wind turbines is important in two respects: (a) the proximity of wind turbines to roads causes airborne pollution caused by wind turbines to affect road transport. On the other hand, in addition to affecting the road perspective, the movement of the turbine blades will cause the roads to lie in the shadow of the blades of the turbines; (b) Because of the huge weight of wind turbine, blades, and wind turbine bases, the location of wind farms near roads is of great importance in reducing costs, as one of the significant costs of installation is the cost of transportation.

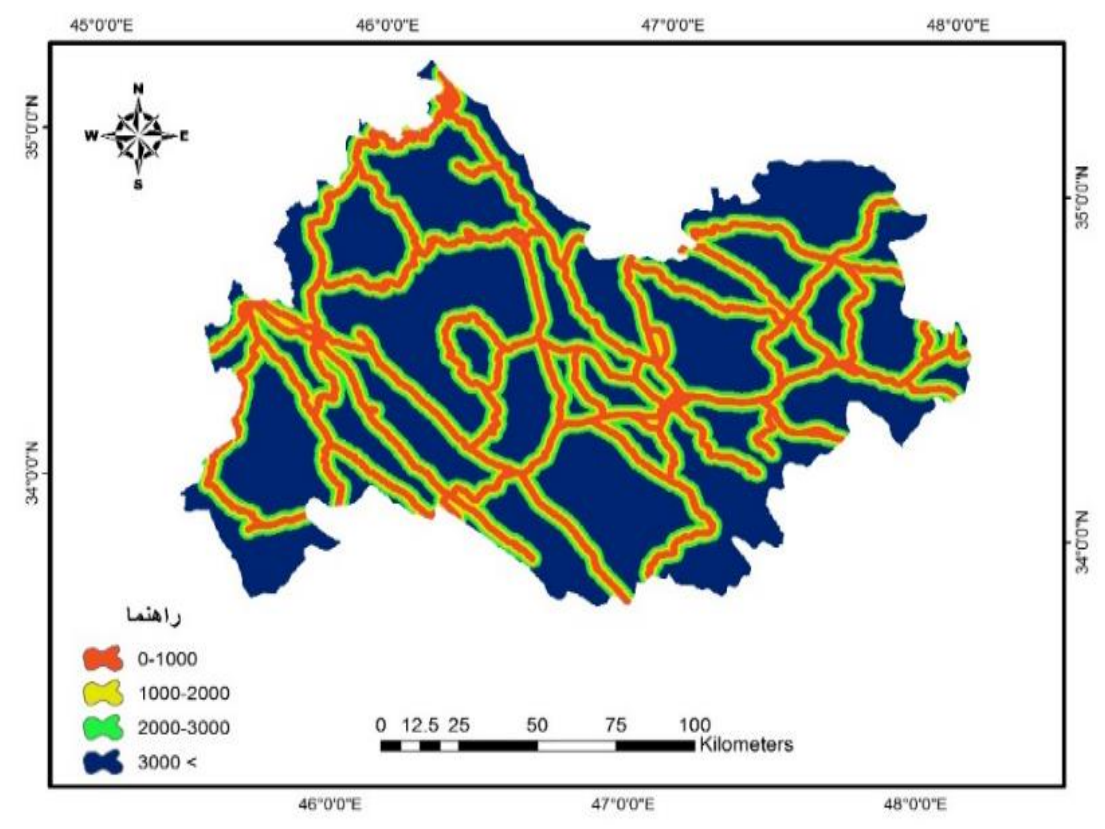

Figure 4: Distance classification of the road

\subsubsection{Rainfall layer}

Rainfall can be considered as the most important factor involved directly in hydrological cycle. The rainwater is meant to be the whole of the atmospheric precipitation that should penetrate to the ground. Therefore, the high rainfall during one year on one side indicates the high humidity in the area, which is the most important factor in absorbing short-wave radiation. On the other hand, it indicates the presence of high suspended particles in the atmosphere of that region, which is involved both in absorption and reflection of short wave radiation. After 
averaging 30 years of precipitation, it was taken from the Meteorological Organization, the formation of rainfall layer were put in four classes.

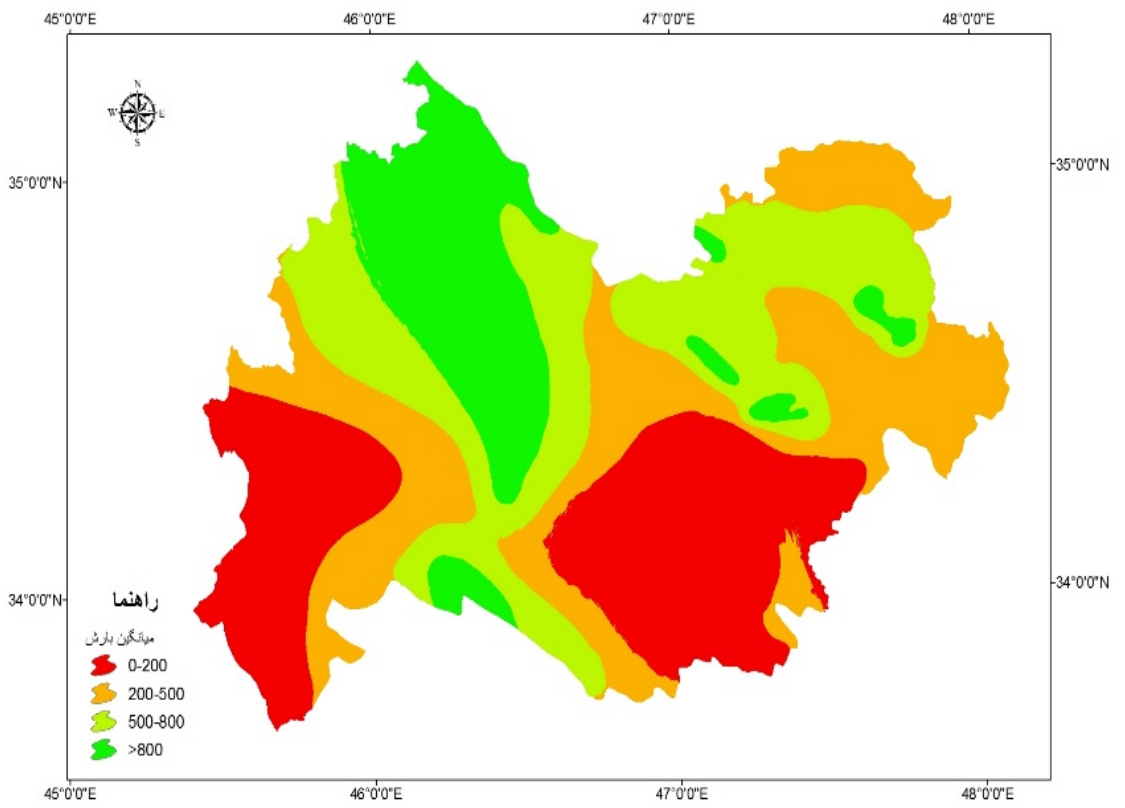

Figure 5: Average precipitation of thirty years in Kermanshah province

\subsection{Geomorphology}

Geomorphologic maps can be used as the appropriate criteria for determining suitable areas for wind farms in areas lacking the data on the shape of the land. Vast plains with mild slopes, Pediments and cones (depending on their size and location) are considered as optimal locations for execution.

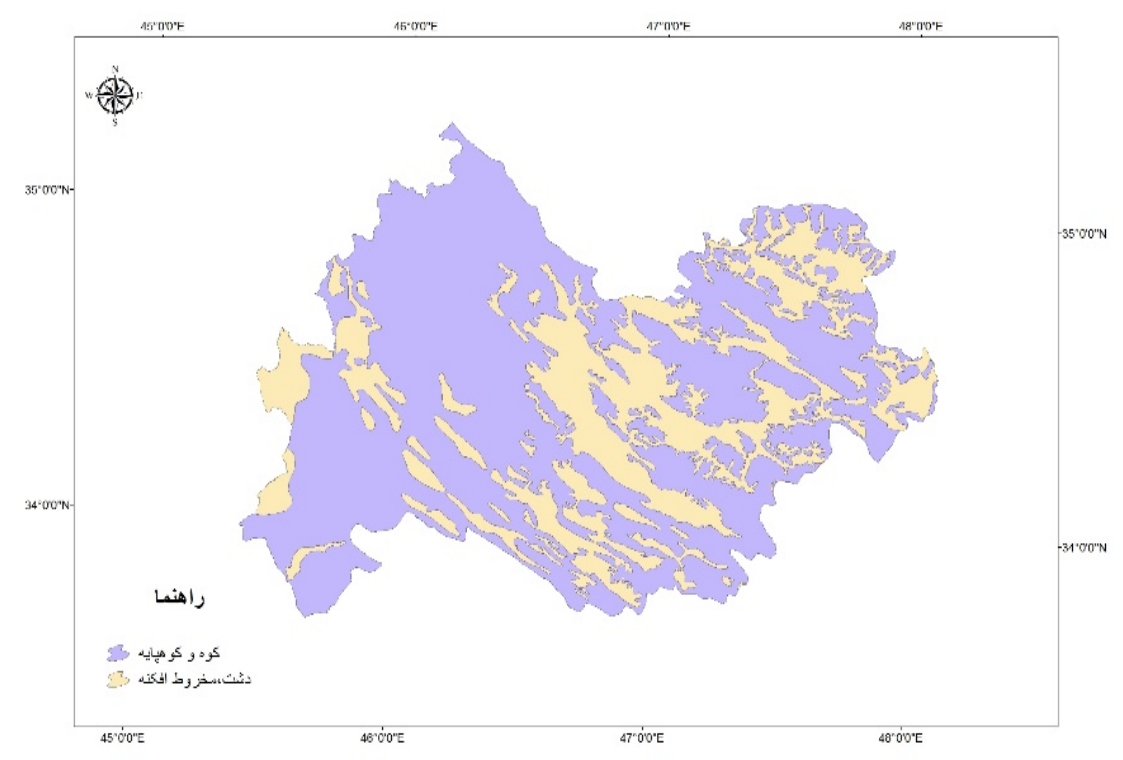

Figure 6: Geomorphologic classification in Kermanshah province

\subsubsection{Distance from the city}

Major consumers of electrical energy are cities, villages, agricultural wells, industries, and industrial towns. For the vicinity of the site where the power plant of electrical energy source to the points of consumption, attention is needed to be paid to the dispersion of consumers. The proximity of the power plant to the loading centers is an important feature and that the centers of consumption in the future should be specified because the purpose of the nearby power plants is to reduce consumption costs to the centers and to reduce energy losses. To provide 
this layer, 1: 50000 maps were prepared by Mapping Organization, and Buffer function in ArcGIS 10 software was used based on the distance from the population points for valuation.

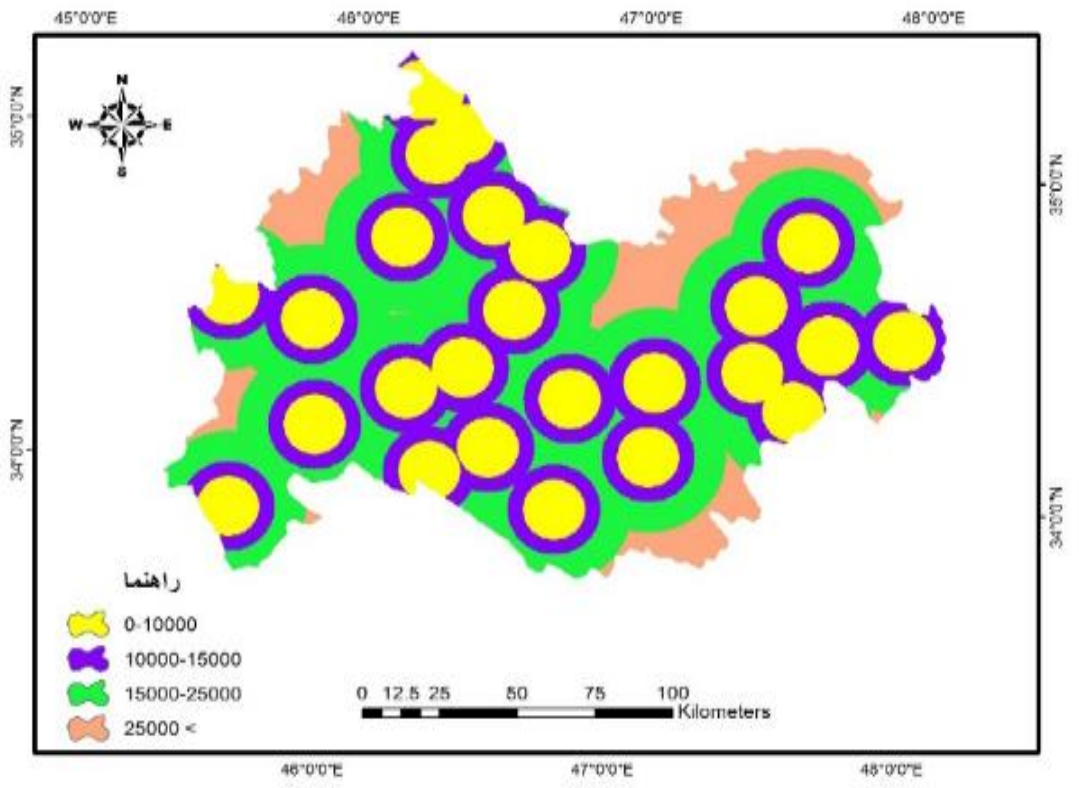

Figure 7: Distance classes from urban boundaries

\subsubsection{Land use layer}

Land use map is indicative of the use of a piece of land (such as farmland, residential areas, and forest areas). Proper land use information for any type of activity and planning in the country is quintessential. Land use layer for the province was obtained from maps of 1.25000 and was updated using satellite imagery.

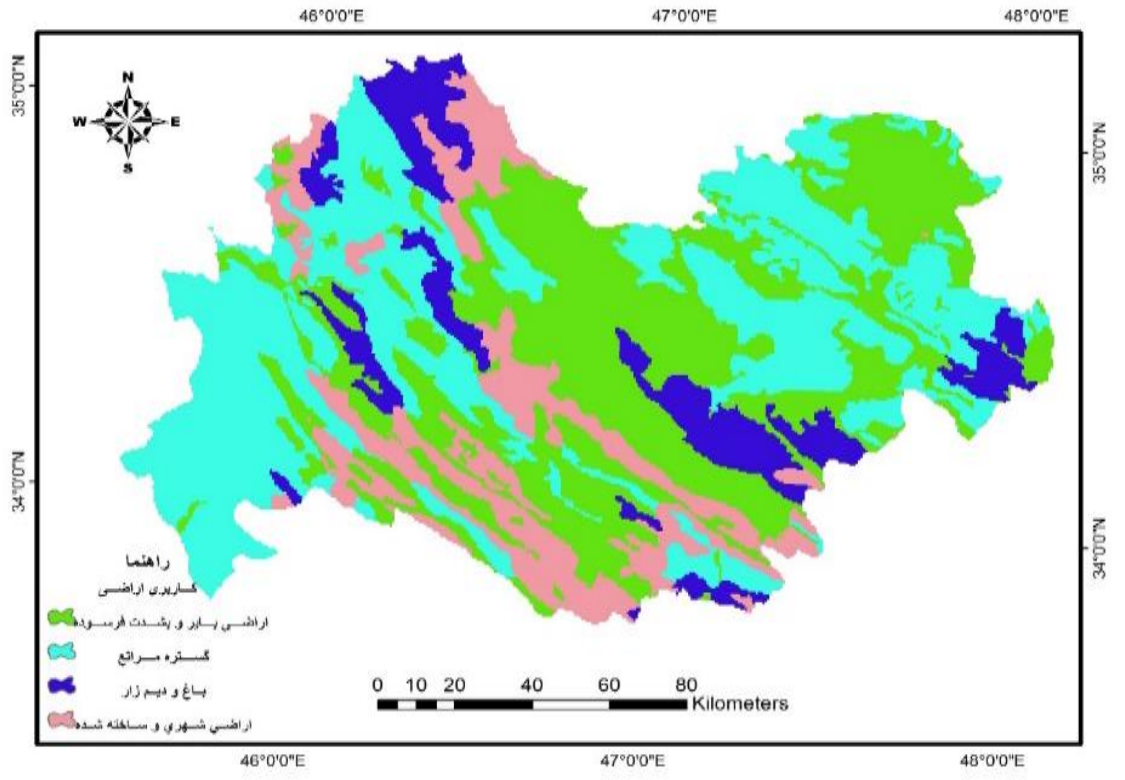

Figure 8: Land use classification

\subsubsection{Vegetation classification layer}

Vegetation increases the air turbulence and reduces wind speed while the height of the base of the common turbines is about 50 meters (164 ft). The height of the turbine blade can be 25 meters below. Placing wind turbines in areas with a vegetation above 10 meters will increase the risk of damage to wind turbines caused by air turbulences. Vegetation factor is one of the important factors in the field of wind farms, so it must be carefully studied and categorized. In the classification of this layer, shorter plants were considered more appropriate. 


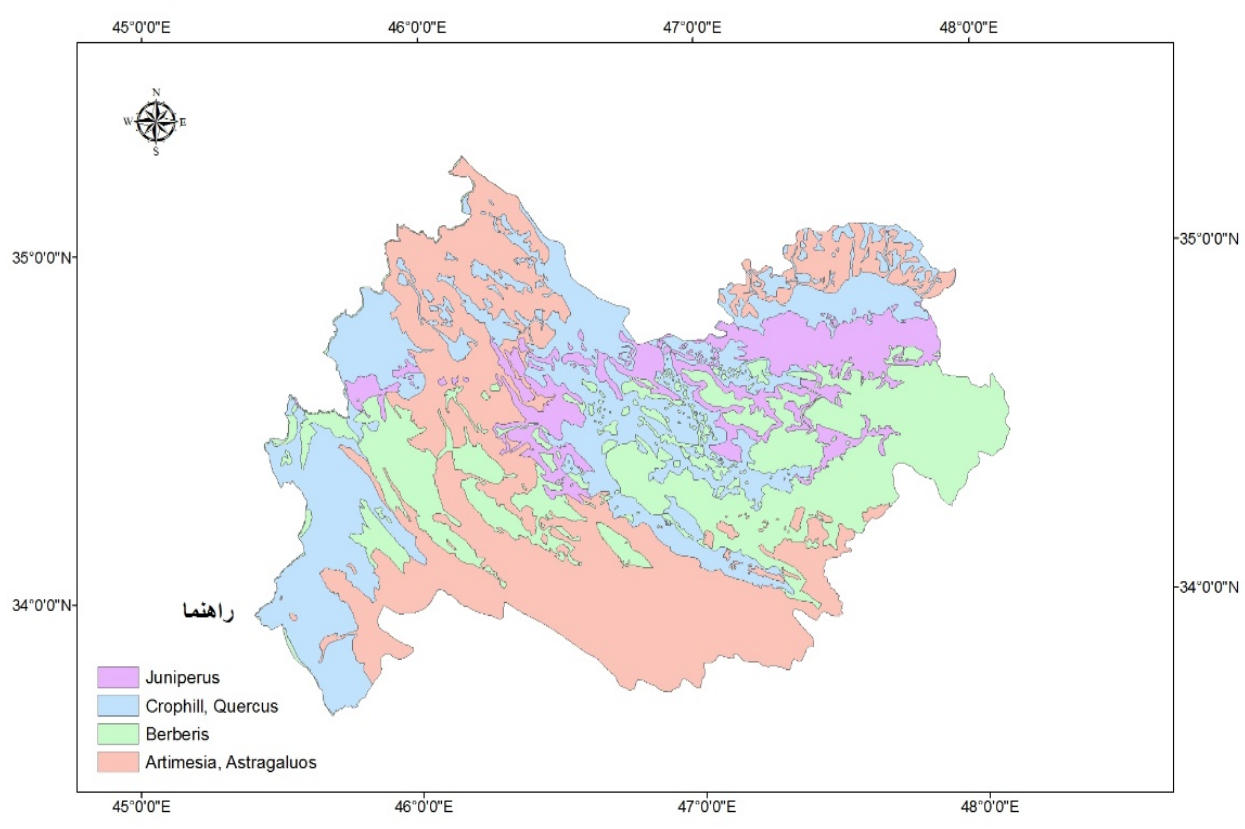

Figure 9: Vegetation layer classification

\subsubsection{Distance from protected areas layer}

The human misuse of land and mismanagement nowadays represents the irrational use of man from land. Extensive lands with high conservation value, which are selected to preserve and restore plant habitats and animal habitats, are called protected areas. Such areas are protected due to having valuable or valuable meadows and beautiful landscapes and to protect them from the destruction of vegetation and animals that are present in them. Because of the addition of a technology factor to the natural landscape, wind farms have a negative impact on the inherent nature of these areas.

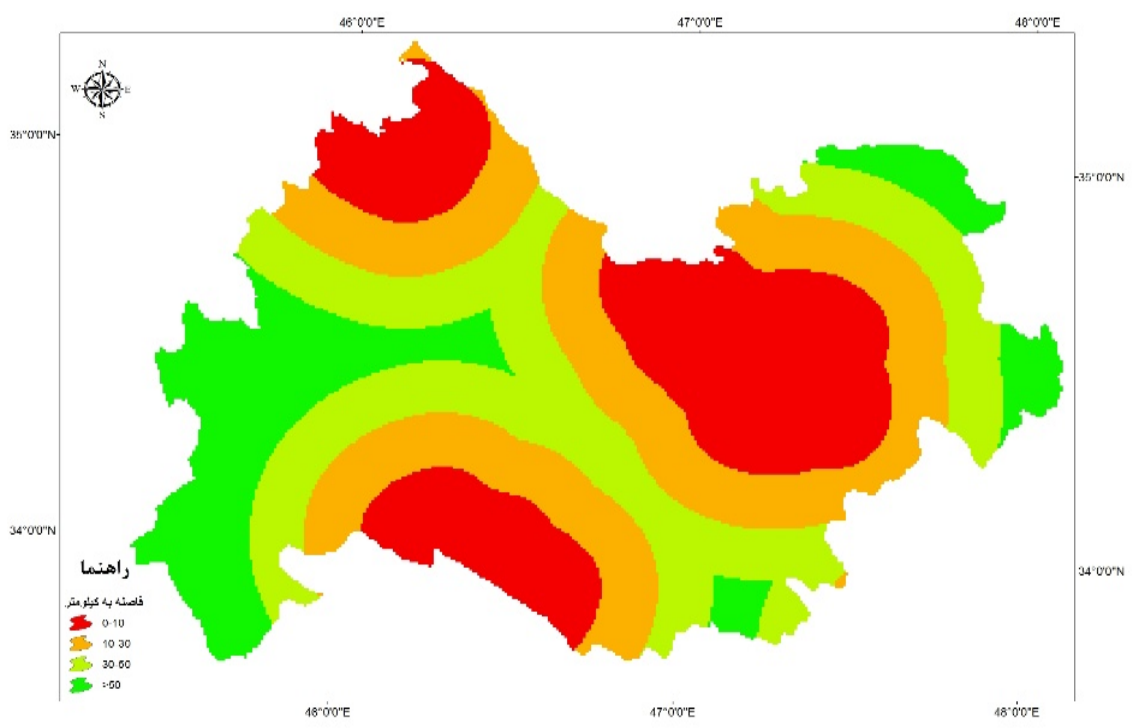

Figure 10: Distance classification of protected areas

\subsubsection{Height layer}

Height criterion include altitude from the sea level. The height should be such that it does not cause difficulty to transfer the equipment. On the other hand, height factor affects the wind speed. Indeed, as the height increases, the wind speed increases, but increasing the height will reduce the pressure and temperature of the air and will affect the amount and power of the turbine. 


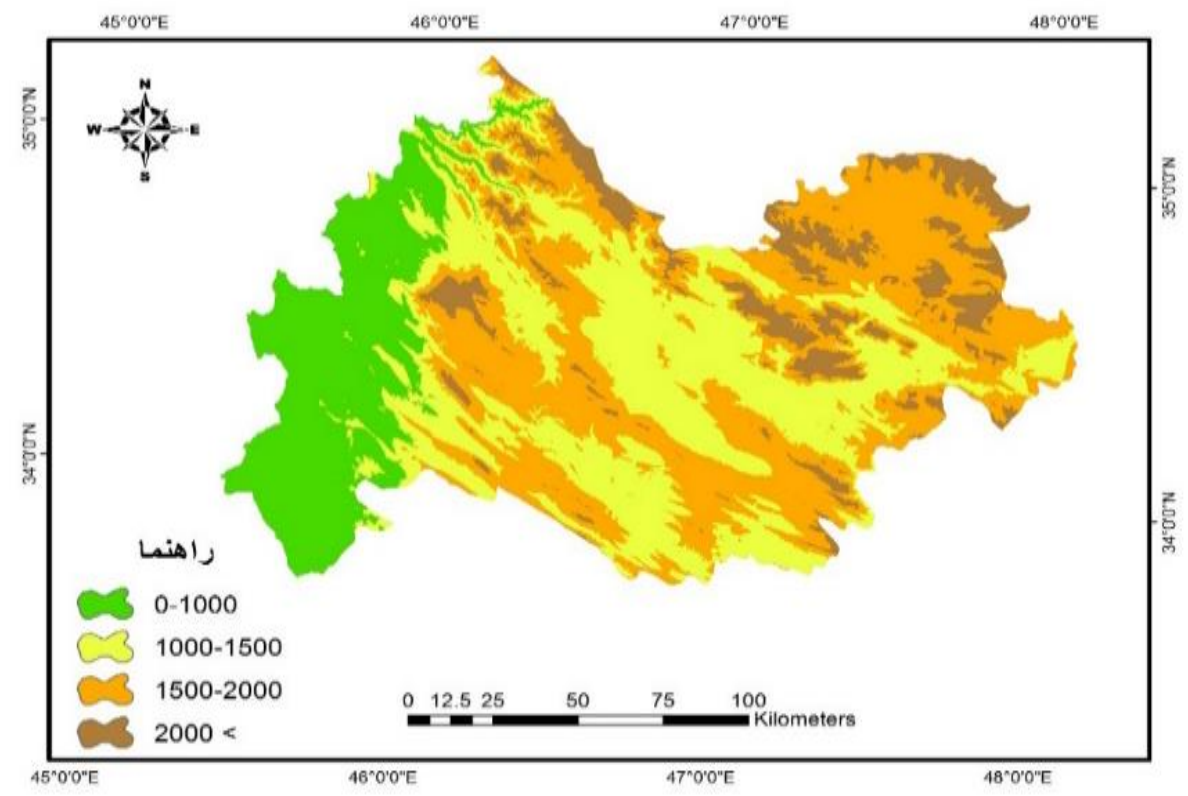

Figure 11: Stiffness classification in Kermanshah province

\subsubsection{Fault}

Faults are a linear impairment, along with displacement that have contributed to the development and formulation of Iranian sedimentary basins and, with their activities, have created a lot of changes in the geology and land sustainability. Since faults are the weak points of the earth's crust and make possible the centralized release of energy inside the earth, sites with more resistance and low seismicity, are considered as the most suitable place for the installation of wind farms (Samadi and Tika, 2007, p. 78). The fault line layer developed by Geology Organization was used. After turning this vector layer into a raster layer, due to the fact that the fault lines do not act linearly but they have a radius of influence, using the Buffer function in terms of the radius of action, a confidence interval was determined for them.

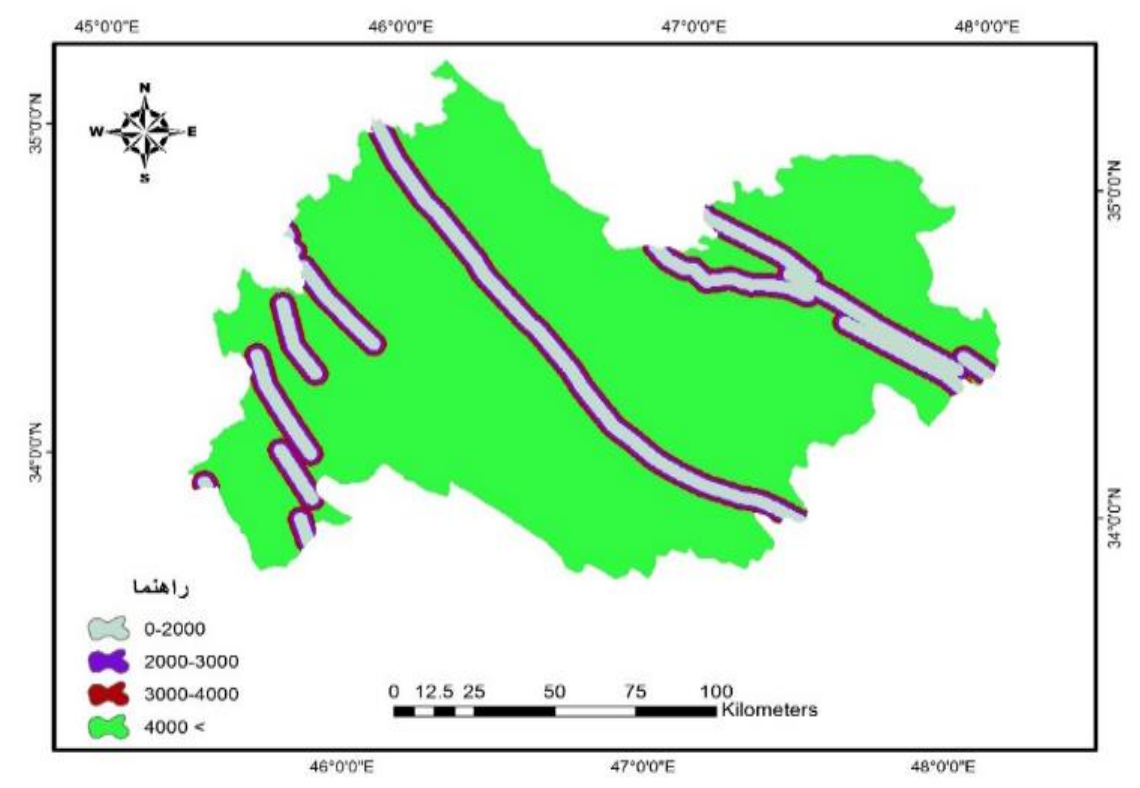

Figure 12: Distance from faults classes

\subsubsection{Geological layer}

Review of the related literature shows that it is difficult to classify a specific type of rock in terms of resilience in a particular locality in a classification because, in addition to the type and composition of mineralogy, many other factors also affect rock resistance. However, it can generally be assumed that resistant igneous rocks are stronger than sedimentary rocks, and high densities and densely deposited stones are more resistant than low density and low density sediments. Earth's geology, which is extracted from the geological layer and soil type, is 
also one of the factors involved in the location of wind turbines. Because the wind turbines are in the ground for several meters, the hardness of the earth will increase the cost of installation.

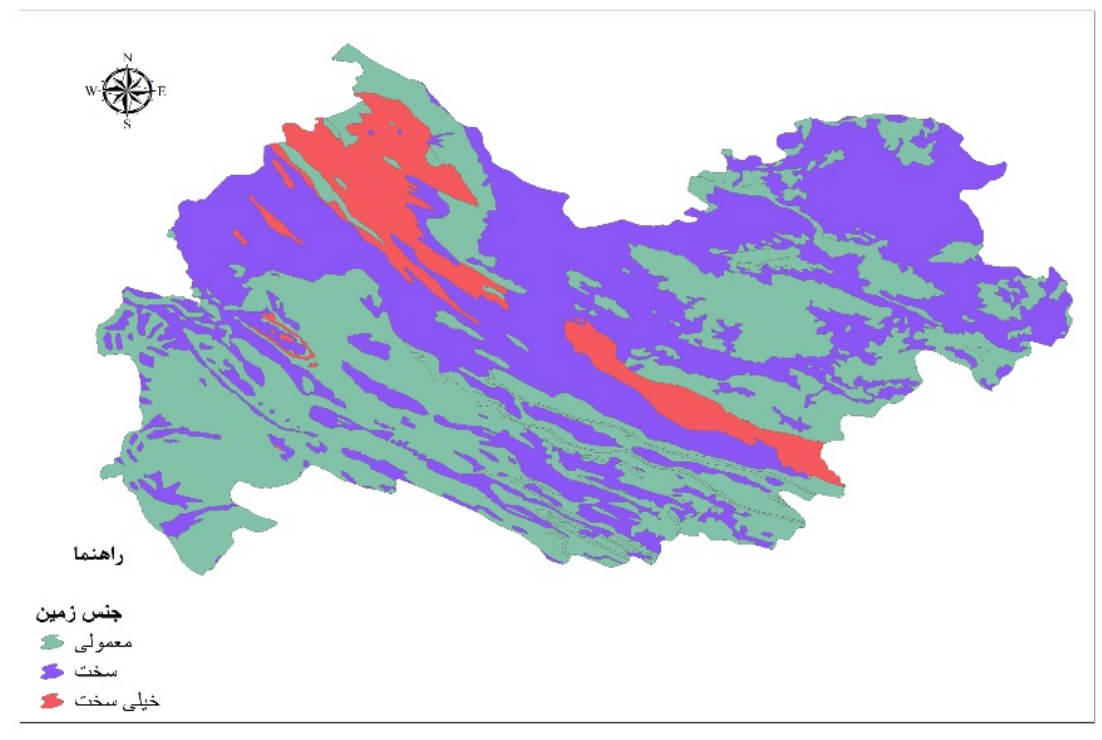

Figure 13: Land quality

\subsubsection{Constraint layer}

Constraints are obstacles imposed either by man or by nature and preventing them from choosing alternatives. Determining the constraints is generally based on existing resources and arrangements, and includes professional judgments. For example, the cost of setting up facilities or costs for implementing an environmental protection strategy should not exceed a certain limit. These types of constraints are usually called budget constraints. Other examples are the existence of land or other resources. Constraints impose barriers to the set of decision choices. An alternative becomes executable if it does not have any constraints. Alternatives that cannot meet the constraints are inevitably one of the ineligible ones that are of two types: Boolean or logical limitation, and objective constraint. For example, in the field of wind turbine location, we assume that the appropriate option should be outside the city limits or have at least 4 meters per second wind speed. Two constraints apply to the set of options. Such restrictions are called Boolean or logical constraints. Another example for the objective constraint is that the land suitable for installation should be 10 hectares. This type of constraint is the type of objective constraint. From another aspect, as in the second chapter, the constraints are divided into compensatory and non-compensatory parts. To prepare the boundary layer of the studied region, all the layers that were possible to create constraints were first introduced as Boolean, then by applying the And operator among all layers, the layer of constraints were obtained and the pixels that had zero value were considered as non-executable options. Such constraints are logical and non-compensatory, as shown in Table 10. In this research, about 19327 square kilometers of province areas were considered impossible to install for a wind farm and 5492 square kilometers were considered as capable of being installed.

Table 1: Constraint layer and distances from areas and boundaries

\begin{tabular}{|c|c|}
\hline Type of boundary & The desired distance (m) \\
\hline The distance from the city limits & 5000 \\
\hline The distance from the village range & 2000 \\
\hline Riverside & 500 \\
\hline Fault boundary & 1000 \\
\hline Distance from protected areas & 2000 \\
\hline Height & 2000 \\
\hline Airport & 5000 \\
\hline City area & 5000 \\
\hline
\end{tabular}




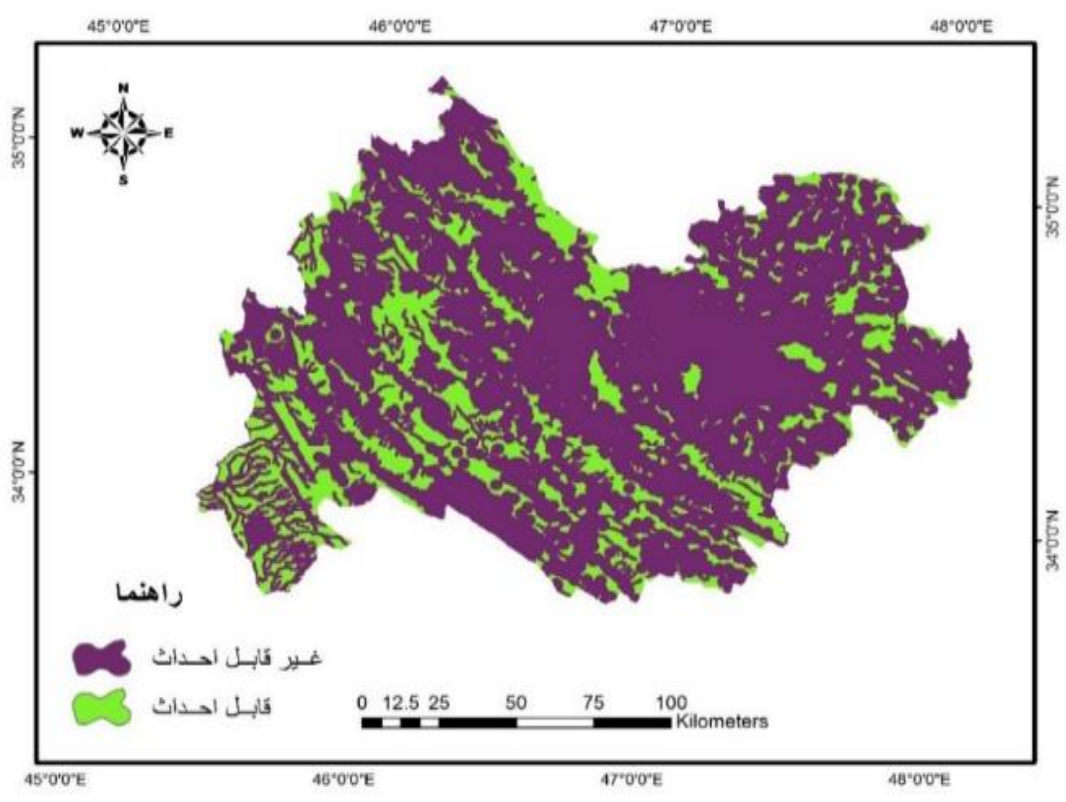

Figure 14: Areas suitable for installation and not suitable for installation

\subsection{Analytical Network Process (ANP) model}

Analytical network process is one of the multi-criteria decision-making techniques developed by the Analytical Hierarchy Process (AHP). This model was developed by Saati in 1996, following hierarchical analysis limitations in solving problems and evaluating the cumulative importance of all indicators within an evaluation model, combining communications and feedback within a decision-making system (García-Melon et al, 2009). Analytical network process provides a comprehensive and powerful method for making accurate decisions using empirical information or individual judgments of each decision maker. By providing a structure for organizing different criteria and evaluating the importance and priority of each of them for options, it makes decision making easy. This process is a decision-making model based on the mathematics and human psychological algorithm that is consistent with the basic structure of the human mind (Nakhaei Kamalabadi et al., 2010). This model is a general form of the AHP model, which expresses the relationships between elements as a network by describing communications and paths of elements (Banar et al, 2006). Although both models obtain priorities through paired comparisons, there are differences between them. Saati states in the introduction to the principles of analytical network process that the ANP is a basic and essential step in decision-making process. Due to the negligence of the traditional approach due to its linear structure, it takes into account the reclaimability structure. Considering all its pros and cons, it can be considered a lost phase in the decision making process (Saati, 1999). Hence, the most important distinction between this method and the hierarchy method is the effectiveness and affectedness of the criteria. Although this process does not require a hierarchical structure, like the AHP, it is derived from the relative scale of all the effects and judgments of individuals, and by these scales, accurate prediction is made about them (WeiChang, 2009). Analytical network process consists of three basic steps:

Step 1: Illustrating the model and subject structure: The subject should be clearly stated and analyzed within a logical system such as a network. This network structure can be shaped by decision-makers through methods such as hurricanes or mathematical methods such as DEMATEL.

Step 2: Illustrating pairwise comparison matrices and extracting their priority vector: This is the same step as analytical hierarchy process. First, the importance or preference of the criteria or sub-criteria are questioned and evaluated by expert or experts according to the control criterion in the range of one to nine (or with the value of inverted numerals.

Then, the degree of incompatibility of judgments is measured by a coefficient known as the Incompatibility Rate (I.R). If this coefficient is less than 0.1, compatibility in judgments is acceptable; otherwise, judgments should be reviewed. After ensuring that the judgments are consistent, it is time to determine the coefficients of importance of the criteria. If the calculations of this method are made using the Super Decision software, then a method called the Eigen vector (in accordance with the following equation) is used to determine the matrix priority vector. 
Relation (1)

$$
\mathrm{A}_{\mathrm{W}}=\lambda \max { }^{W}
$$

where $\mathrm{A}$ is the pairwise comparison matrix, $\mathrm{W}$ is the Eigen vector, and $\mathrm{y}$ is the highest numerical value and $\lambda \max$ is the largest special value of the matrix A or super matrix.

Step 3: Illustrating super matrix: Super matrix has a similar concept to the Markov chain. For this purpose, to calculate the final priorities of the components in systems with dependent variables, all the priority vectors derived from the pairwise comparison matrices enters the column matrix. Finally, by normalizing the supermatrix coefficients with the coefficients of the clusters, the final weights of the elements are calculated. The final weight is obtained from the combination of all matrices and clusters. The functions of the options are valued by the weights of criteria and sub-criteria and added to the general priorities for each option (Wolfslehner et al; 2005, 160). The model classifies the options from the highest importance to the least importance according to judgments and human assessments as well as based on the closer or farther options (Banner et al. 2008, 748).

\section{Results}

Designing suitable areas for the construction of wind farms can be considered as a system in which all relevant criteria should be selected as optimal. After providing information layers in a spatial information system for optimal data management, the spatial database was created and the layers were placed in. In order to determine the importance of each criterion, after consulting with experts who had the experience of developing a network process model, a model of network analysis was created with respect to the creation of clusters and sub-criteria. The goal of weighting is to find the importance of each criterion to the other criterion. The weight of the criteria in this research was obtained according to the average opinions of experts and professionals with social, cultural, environmental and economic perspectives. Thus, 23 experts, each of which were experts in the field of economic, environmental and socio-cultural views, had been given a questionnaire. After giving the necessary explanations, they were asked to compare the two criteria to a number from one to nine, indicating that the criteria were superior to each other. In order to create a relationship between criteria and sub-criteria, a network process was created as shown in Figure 15. Then, considering their average reviews and running Super Decision software, the weight of the clusters and sub-criteria was obtained according to Table 1.

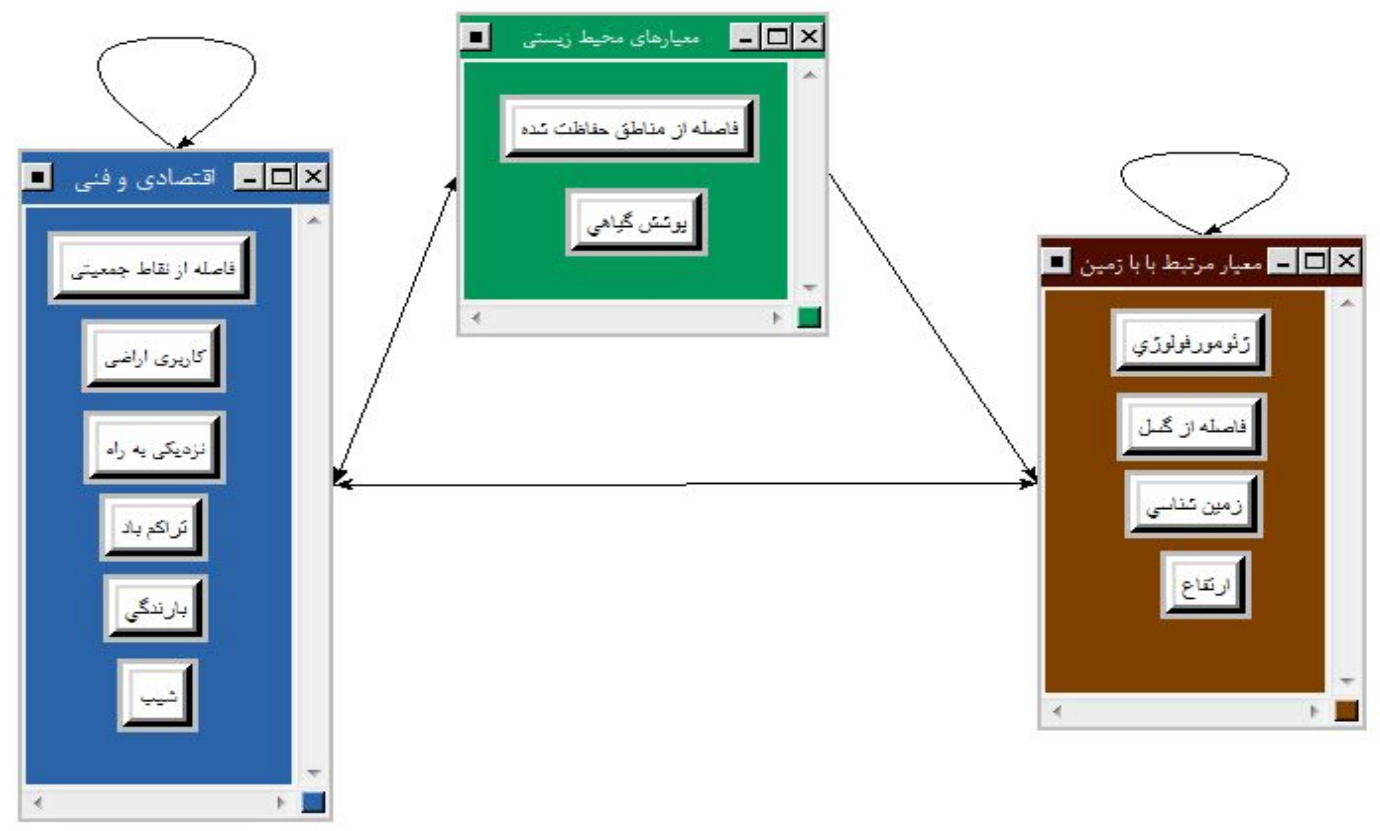

Figure 15: Developing the relationship between criteria for network analysis 
Table 2: Clustering of the criteria and the final weight of each criterion

\begin{tabular}{|c|c|c|c|c|}
\hline Cluster & $\begin{array}{l}\text { Weight of } \\
\text { the cluster }\end{array}$ & Criterion & $\begin{array}{l}\text { General weight of } \\
\text { criterion }\end{array}$ & $\begin{array}{l}\text { final weight of } \\
\text { criterion }\end{array}$ \\
\hline \multirow{6}{*}{$\begin{array}{l}\text { Economic and } \\
\text { technical }\end{array}$} & \multirow{6}{*}{0.42} & Wind density & 0.32 & 0.1344 \\
\hline & & Slope & 0.17 & 0.0714 \\
\hline & & Proximity to roads & 0.063 & 0.264 \\
\hline & & precipitation & 0.005 & 0.002 \\
\hline & & $\begin{array}{l}\text { Distance from population } \\
\text { points }\end{array}$ & 0.13 & 0.546 \\
\hline & & Land use & 0.06 & 0.0672 \\
\hline \multirow[b]{2}{*}{ Environmental } & \multirow[b]{2}{*}{0.39} & Vegetation & 0.064 & 0.0249 \\
\hline & & $\begin{array}{l}\text { Distance from protected } \\
\text { areas }\end{array}$ & 0.004 & 0.0015 \\
\hline \multirow{4}{*}{$\begin{array}{l}\text { Land-related } \\
\text { factors }\end{array}$} & \multirow{4}{*}{0.18} & Height & 0.069 & 0.0124 \\
\hline & & Distance from the fault & 0.003 & 0.0005 \\
\hline & & Geology & 0.007 & 0.0012 \\
\hline & & Geomorphology & 0.005 & 0.0009 \\
\hline
\end{tabular}

After determining the effective factors in locating the wind power plant and preparing all the information layers using the analytical functions of GIS and determining the weight of the effective criteria for locating the power plant based on cluster analysis, the index overlapping method was used for combining the layers. Finally, the final map was obtained as a raster one. To achieve better results, using the natural disruption method, the whole area was classified into four classes from weak to very good. This method is designed to determine the best arrangement of values for different classes. This method seeks to minimize the average deviation of each class of the middle class and maximize the deviation of each class from the average of other classes; in other words, this data classification method aims to reduce the variance in classes and maximize the variance between classes. Finally, the map of susceptible areas for wind power plants in Kermanshah province was obtained as shown in Figure 16.

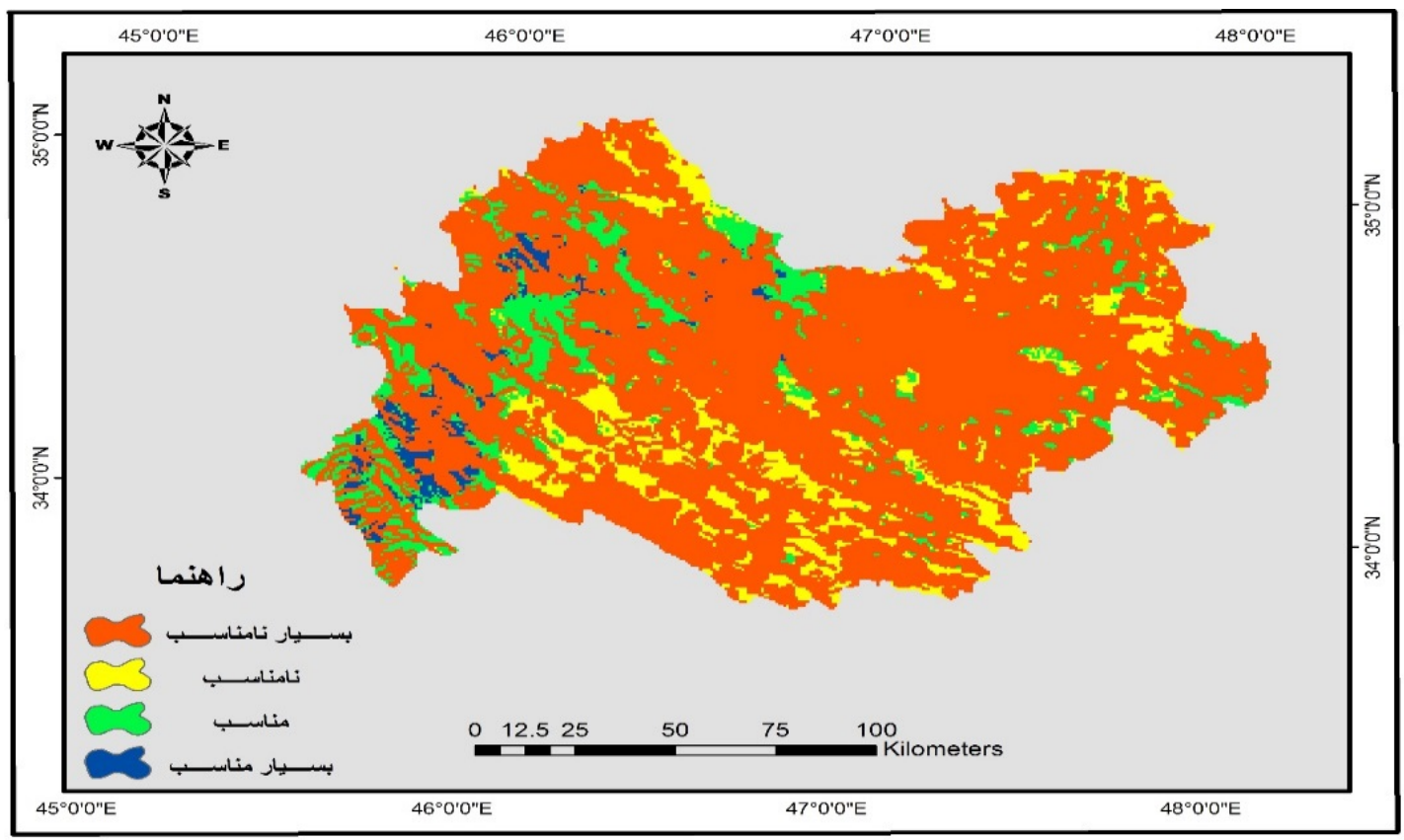

Figure 16: Classification of different areas of the province for the construction of wind farms 


\section{Discussion}

Electricity supply for all villages will not be economical due to the distribution network of villages in different parts of Kermanshah province. Using natural potential such as wind energy can be a good alternative to energy in these areas. In this research, considering the three decision making points and using analytic network process, suitable sites for the construction of wind farms were determined. In the analytical network process by creating primary clusters and sub-clusters, in addition to considering whether cluster dependence is involved, the relationship between the main clusters is also considered. In this research, the criterion of wind energy density was the most important in location. Other criteria had significant differences. In total, there are three important criteria in decision making i.e. wind density, slope, and land use. Based on the results, most areas of the province, an area of $18084.785 \mathrm{~km}^{2}$ is not capable of constructing a wind power plant with respect to the mentioned variables, while only an area of about $404.173 \mathrm{~km}^{2}$ of the province is suitable to construct a power plant with respect to the conditions mentioned. As shown in Fig. 16, most suitable areas are located in the eastern part of the study area, which are paved and near to densely populated and scattered villages. These options, while providing the speed criterion, are also more important than other parts in other criteria. Perhaps it is much more than a provincial average due to its location in the area with wind speed. Because wind speed is a very important factor in choosing options. Studies on the potential of renewable energy, especially wind energy, are very limited in Iran, and according to studies carried out in various sources, studies have been less geographical and more descriptive. The only case comparable with the present study is the location of gas power plants using the GIS, in which Boolean, index and fuzzy overlapping have been used. Another study carried out in this respect is surveying wind potential of 11 synoptic stations in Yazd province out without the use of geographic information system and has been done descriptively. A sample of research has been carried out to study the potential of wind in the province of Sistan and Baluchestan, which is also done regardless of the location of the criteria with the climate perspective

\section{Conclusion}

It can be concluded that in Kermanshah province, the cities of Qasr Shirin and Gilan-e Gharb and parts of the city of Sallat Baba Jani have favorable conditions for the construction of an wind power plant, while in the western parts of the province due to unbalanced conditions such as slope and vegetation coverings, the conditions has been, in fact, unfavorable. With average wind conditions, the construction of wind turbines will be economical, and part of electricity needed can be met. This can be extended to other provinces of the country, which has not yet been studied in some regions and provinces with an average wind speed more than Kermanshah province. The designated areas as optimal locations cannot be completely comprehensive, so they are only introduced for more detailed and comprehensive studies. Given the limited resources of fossil fuels, the increase of fuel carriers in Iran, and the benefits of sustainable energies it is suggested to study the locations suitable for sustainable energy plants, including solar, wind, geothermal, and tidal using geographical information systems and multi-criteria decision-making methods. It is also suggested that appropriate areas be identified with other multi-criteria decision-making methods and the results be compared with those of this study.

\section{References}

[1] Beheshtifar, S., Mesgari, M., Valadan, J., and Karimi, M., (2011), Using Fuzzy Logic in GIS Environment for Site Selection of Gas Power Plant, Journal of Civil And Surveying Engineering, 10th Year, No. 4, Vol. 44, Pp. 583-595

[2] Saedi, D., Nematollahi, O., and Alemrajabi, A A., (2011), Assessing the wind energy potential of North Khorasan province in Iran, Energy Engineering and Managemet, First Year, No. 1, 49-56

[3] Soltani, S. B., Gholamian, S.A., and Dazjani Farahani, K., (2011), Investigation of wind energy potential in Amirabad basin to allow the establishment of a wind power plant, Iranian Journal of Energy, Vol. 13, No. 13, 1-16

[4] Mohammadi, H., Rostami Jalilian, N., Taghavi, F., and Shamsipour, A.A., (2012), Evaluation of Wind Energy Potential in Kermanshah Province, Physical Geography Research, 44th Year, No. 2, 19-23

[5] Nakhai Kamalabadi, I., Amirabadi, M., and Mohammadpour, (2002), Selecting the Optimal Strategy Based on SWOT Analysis and Analysis Network Process (ANP); Case Study: Arak Petrochemical Company, Industrial Management Quarterly, 11, 21-33

[6] Noorollah, Y., Ashraf, M.A., and Zamani, M, (2011), West Regional Electricity Wind Power Using Geographic Information System (GIS), Iranian Journal of Energy, Vol. 14, No. 1-21

[7] Banar M, Kose B.M. and Ozkan A. (2006), 'Choosing a municipal landfill site by Analytical Network Process', Article of Environ Geol, 52, 741-751.

[8] EWEA. Powering the energy debate. 2010. European Wind Energy Association. 11-54.

[9] Garcia-Melon, M., Ferris-Onate, J., Aznar-Bellver, J., Aragones-Beltran, P. and Poveda- Bautista, R. 'Farmland appraisal based on the Analytical Network Process', J. Glob. Optim., Vol. 42, (2009). Pp. 143-155

[10] Groothuis P., Groothuis D., Whitehead C., 2008. Green vs. green: measuring the compensation required to site electrical generation windmills in a view shed. Energy Policy. 36.1545-1550.

[11] Jiang H., Eastman R., 2000. Application of fuzzy measures in multi-criteria evaluation In GIS. International Journal of Geographic Information Systems. 142. 173-184.

[12] Lee A., Chen H., Kang H., 2009. Mulit-criteria decision making on strategy of wind farms. Renew Energy. 34.120-126.

[13] McWilliam MK, van Kooten GC, Crawford C., 2012. A method for optimizing them location of wind farms. Renew Energy. 48. $287-299$.

[14] Nguyen, T. N., and C. T. Tran, 2005. Strategies for Promotion of Energy Efficient and Cleaner Technologies in the Power Sector. National Reports (issue 1\&2) submitted to the Asian Regional Research Program in Energy Environment and Climate, Phase III. 
[15] Prabamroong, Ariyawat., Kasemsan Manomaiphiboon, Wanvisa Chanaprasert, and Nuttee ajpreeja, (2009). Development of a Gis Decision Support System for Wind Farm Installations in Thailand: Current State and Results. World Renewable Energy Congress 2009 Asia, p.p 690-695.

[16] Resch G., Haas, R., Faber, T., 2007, the future potential for renewable energies - Assessment of their realizable mid-term potential up to 2020 at global scale. Final report of a study on behalf of International Energy Agency, Renewable Policy Unit, Vienna Austria, 323.

[17] Saaty TL. Decision making with dependence and feedback: the Analytical Network Process. Pittsburgh, PA: RWS Publication; 1996.

[18] Tegou L., Polatidis H., Haralambopoulos D., 2010. Environmental management framework for wind farm siting: methodology and case study. J Environ Manag .91(11):2134247.

[19] Wolfslehner, B., H. Vacik \& M.J. Lexer, 2005. Application of the Analytical Network Process in multi-criteria analysis of sustainable forest management, Forest Ecology and Management, 207: 157-170.

[20] Wolsink M., 2010. Near-shore wind power protected seascapes. Environmentalist's attitudes, and the technocratic planning perspective. Land Use Policy. 27(2).195-203. 